\title{
A Study on the Schooling and Cultural Identity of Cross-border Ethnics in Yunnan
}

\author{
Gu He \\ Yunnan University of Finance and Economics, \\ Kun Ming, Yun Nan 650221 \\ ghguhe@163.com
}

\begin{abstract}
There are several key problems for the schooling and cultural identity of cross-border ethnics in Yunnan: school, family and community; schooling settings; social-economic development. It should establish a social mechanism to develop schooling and culture; plan schooling and cultural development; strengthening family, school and community participation; develop inclusive and diversity culture.
\end{abstract}

\section{Keywords-Schooling; Cultural Identity; Cross-border Ethnics}

There are more than 30 cross-border ethnic groups inhabited by China's long border regions. Among them, 16 ethnic groups lived in border regions of Yunnan province, and they have backward educational and cultural development. On the other hand, due to the special geopolitical and socio-cultural environment, the cross-border ethnics have formed more complex and diverse cultural identity. Schooling and cultural identity are closely related and interact with each other. With the process of economic and social development, the development of education and cultural identity is facing a rapidly changing social environment, and a series of problems have emerged for schooling and cultural identity.

\section{SCHOOLING AND CULTURAL IDENTITY OF CROSS-BORDER ETHNICS IN YUNNAN}

\section{A. School, family and community}

Traditionally, cross-border ethnic education is rooted in its society, inheriting and sustaining its social and cultural development and shaping its cultural identity. Through traditional education, cross-border ethnics learned the production knowledge inherited by ethnic groups, the common customs and moral culture they shared. On this basis, they formed a sense of belonging and a cultural identity to their families, communities, and ethnic groups. Meanwhile, based on the recognition of ethnic cultures, cross-border ethnics participate in traditional education activities and assume the responsibility of educating other ethnic members.

Modern education is different from the traditional education of the cross-border ethnics. In the border ethnic areas, schools are established as a social mechanism and social culture. This type of education has fragmented the connections between students and their families and communities. Cross-border ethnic students who have significant differences in mainstream culture will have difficulties and obstacles in their learning and cultural identity.

To the distribution of the schools, most of the cross-border ethnic groups in Yunnan live in rural mountainous areas, with scattered living, inconvenient transportation, and economic backwardness. In the $20^{\text {th }} 90 \mathrm{~s}$, China gradually began to adjust the distribution of primary and secondary schools. At the end of 2011, Yunnan withdrew 9,308 primary schools and 112 secondary schools. In the same period, there were also many primary and secondary schools in the ethnic areas on the border. For example, in Funing County in April 2011, it cancelled 248 schools, including 244 teaching centers and 4 primary schools. Overall, the school's distribution adjustment is conducive to improving the quality of education, improving the allocation of teachers, and improving the effectiveness of education. In border areas, it also promotes the exchange and cooperation among students of many ethnic groups. On the other hand, the adjustment of the distribution of schools in these areas and the rise of boarding schools at the same time also caused some problems, which have an important impact on the schooling and cultural identity of cross-border ethnic groups. Schooling interrupts the traditional language and cultural processes of ethnic groups to some extent. Due to the school's distribution adjustment, some teaching sites in the communities were removed and many students had to attend schools far away from the family or the village. Most of these schools are boarding schools, which meant these students are reunited with family only on weekends during his schooling. This is not conducive to students' emotional relations with families and communities and their physical and mental status Since the school is separated from the social and cultural environment of cross-border ethnics around family and community, it is also not conducive to develop cultural identity for ethnic groups in this environment, hindering their acceptance of traditional ethnic culture. And at the same time, the academic achievements of ethnic students have negative impacts.

\section{B. Schooling settings}

At present, the curriculum of Yunnan's cross-border ethnic schools is not much different from that of ordinary schools. In terms of bilingual courses, bilingual courses in different regions have significant differences. The "bilingual" teaching 
mode adopted in the border areas of Yunnan is mainly based on Chinese and supplemented by ethnic languages. The schools use the teaching materials of the Chinese version of and Chinese language to guide students to learn the contents of Chinese language textbooks.

Taking Funing County as an example, there are 12 primary schools in the county carrying out bilingual teaching in the first grade or second grade. Among them, the combination of Chinese and Zhuang languages, Chinese and Yao languages, and Chinese and Miao language are the main teaching methods. Text teaching is conducted in Yaobo Elementary School and Xinhua Tuanbao Elementary School, where the Yao people gathers, and bilingual teaching classes are taught in ethnic languages and Mandarin. It is worth noting that many ethnic kids already have basic Chinese listening and speaking skills before they enter primary school in recent years, due to the popularization of television and other media and the development of transportation and communications, which also has led to difficulties in the development of bilingual education. Teachers and local education administrators also believe that the importance of bilingual teaching is limited, and the lack of suitable bilingual teachers has changed the bilingual teaching in many schools to Mandarin monolingual teaching. The cross-border ethnic socio-cultural differences in Yunnan are very obvious, and the demand for bilingual education varies. How to adjust the curriculum settings of schools in border areas such as bilingual education to meet the social development and the actual situation of cross-border ethnic students is also a major challenge.

To other curriculum settings, at present, the education curriculum for ethnic schools in Yunnan border cannot be adapted to the special conditions of these areas. Many curriculum settings do not take into account the cultural differences among ethnic students and lead to poor learning. In recent years, Yunnan has issued relevant policies and measures to support the development of local courses in ethnic areas, local courses that are subject to local economic and social development and teachers' level and meet local needs in order to meet the needs of ethnic groups are still relatively lacking.

\section{Social-economic development}

In recent decades, with growth of China's economy, the state has introduced a series of policies and activities to support ethnic education, which has promoted the development of education in border areas. The state also actively promotes regional balanced development, vigorously supports the development of the economy and various social undertakings in the border areas. However, for a long time, subject to various factors, the economic and social development in the border areas has been slow, and there has been a big gap between the national average and the provincial average. At present, 14 of the 25 border counties in Yunnan belong to the national poverty alleviation priority counties. The economic and social development indicators of other border counties are almost below the average level of the province. Moreover, the level of development between border counties is very different. For example, in terms of per capita public budget revenue, the province's average is 3,613 yuan, and the highest among the 25 border counties is Tengchong County, which is 2,325 yuan, and the lowest Jinping County has only 665 yuan. Although China has fully the teaching of Chinese textbooks, teachers use the combination of local ethnic language and Chinese to explain the meaning of the Chinese language, using ethnic language incorporated compulsory education into the scope of public finance protection, it has enhanced the overall capacity of the central and provincial governments. However, local governments, especially county-level finances, still take a large part of the funding. This is an enormous financial pressure on the border counties that are already very weak economically.

The economic and social development will also affect the cross-border ethnic needs and perceptions of schooling. Due to the economic backwardness of Yunnan's border counties, most of them lacked employment opportunities that matched the modern economy. This made it difficult for the people in these areas to understand the role and value of schooling. Under such circumstances, the development of schooling will enter a vicious circle, lagging behind in economic development and low education level, making local cross-border ethnic people only engage in traditional primitive agricultural activities or engage in low-level work activities. In this process, the benefits of short-term behaviors have also led them to deepen their misunderstanding of schooling, affect their children's attitude towards schooling, and then fall into a situation of low level of education and low level of economic activity. In such an environment, some cross-border ethnics fall into a short-sighted, utilitarian mental state and are reluctant to learn and receive much knowledge.

\section{RECOMMENDATION}

At present, the cross-border ethnic groups in Yunnan still have a large gap with other ethnic groups in terms of culture and education. There are still various difficulties in inheriting ethnic culture and integrating into mainstream society.

\section{A. Establish a social mechanism to develop schooling and} culture

Firstly, it is necessary to modify the educational laws and regulations system. At present, China has formed a compulsory education legal system based on the "Constitution of the People's Republic of China" and the "Education Law of the People's Republic of China" and the "Compulsory Education Law of the People's Republic of China". These legal systems guarantee all people right to receive basic education. In addition, under the guidance of national laws and regulations, departments and regions have also formulated a large number of ethnic education laws and regulations and regulatory documents. For example, the "Decision on Accelerating the Development of Ethnic Education" issued by the State Council on August 11, 2015, and the "Regulations on the Promotion of Ethnic Education in Yunnan Province" promulgated by Yunnan Province in 2013, etc. These laws and policies have further clarified the contents of the organizational education, conditions and guarantees of ethnic education, and promoted the standardization and legalization of the development of ethnic education culture. The key to the play of the guarantee role of educational laws, regulations and policies lies in the implementation. However, the implementation of the national education policy still lacks strict supervision. Due to the unbalanced social and economic development in the border, the ethical education laws and regulations are still not perfect, and there is no comprehensive 
plan-implementation-supervisory organization. In order to ensure effective legal protection for schooling and cultural development in the border areas, the government are required to formulate detailed implementation rules and supporting systems for promoting education and cultural development at the border schools.

For the development of ethnic schooling and culture, the mechanism for ensuring funds is very important. The current funding for basic education in China is shared by multiple levels of governments, and it is necessary to improve the financial responsibility of governments at all levels. The economic and social development in border areas is lagging behind. Funding for basic education and cultural development in these areas should be fully borne by the central government and the provincial government, while state and county governments are mainly responsible for management and service responsibilities. The central government should intensify general transfer payments and special transfer payments for education for special situations in border areas, and give priority to support funding for education and cultural development in border areas with weak educational foundations. Integrate various ethnic education special funds and expand the scale of funds in a timely manner, focusing on solving outstanding problems in bilingual education, teacher training, and cultural and cultural innovation. Local governments at all levels must give irrational support to ethnic education when arranging fiscal transfer payments and financial resources at the same level. Encourage and guide the social forces to support the development of ethnic education and increase the investment in ethnic education.

\section{B. Planning schooling and cultural development}

The ethnic areas on the border of Yunnan are economically impoverished areas, and their education and culture are backward. However, the development of different regions and different ethnic groups is quite different. Some cross-border ethnic groups such as the Dai people have higher levels of education and culture, while some ethnic groups, such as the Lisu and $\mathrm{Nu}$ people, are very backward. Cross-border ethnic groups in different regions have different living environments and educational and cultural standards. In addition, the level of educational and cultural development among the border areas is also very different. The differences in some regions are even far greater than the differences between ethnic groups. Therefore, the development of education and culture in these areas has outstanding imbalances, and there are great differences between ethnic groups and regions. In the process of developing Yunnan's cross-border ethnic education and culture, it must focus on the border areas and cross-border ethnic realities, and adapt them to local conditions and guidelines for classification.

The policies and projects about education and culture are scattered in various fields and departments. It is necessary to integrate these related resources and make better use of these resources to promote border school education and cultural development. It should combine the physical geography, population, and economic and social conditions across the border to facilitate cross-border ethnic students to enter schools and receive cultural services to meet their needs and make arrangements for the layout and adjustment of the schools and cultural sites in the border area.
Efforts are made to improve the quality of teaching. Focusing on the improvement of teaching quality, it will implement the teaching quality improvement plan for primary and secondary schools in the border areas, modify curriculum and teaching, set up the courses about ethnic culture, and other local courses. It must pay attention to the interest and learning attitudes of students from ethnic groups, and the textbooks that are appropriate for the characteristics of ethnic students, reduce the difficulty, and increase the content of indigenous and ethnic knowledge. Cross-border ethnic students can be piloted in the border areas to carry out "three-language teaching," which is the mode of teaching in the native language, Chinese, and neighboring countries.

\section{Strengthening family, school and community participation}

Based on the experience of developed countries, they all attach great importance to family and community participation in the development of ethnic education and culture. For example, the U.S. government encourages the support of the tribal communities to play a role in Native American Indian education. These tribal communities either directly organizes the organization of tribal schools, or participates in the development of tribal language learning and local curriculum content in public schools. The tribal communities also participate in teacher training activities, and many schools recruit teachers from local community members. Australia's education departments at all levels actively take various measures to attract native children and parents to participate in pre-school education, primary education, secondary education decision-making, distribution and evaluation. The government also provides related education and training for indigenous peoples and enhances their relevant skills in participating in the decision-making process while increasing the jobs of indigenous peoples in education management departments and schools.

It can learn from the relevant experiences of developed countries and encourage families and communities to participate in cross-border ethnic schooling and cultural developing. Most of the border areas belong to frontier autonomous prefectures and counties. According to the national regional autonomy law, the right to make appropriate adjustments to the education management system, school forms, school systems, and teaching contents is based on the actual conditions in the region. In order to better develop the education and culture in the border areas, higher authorities should be given more education to ethnic education and encourage cross-border ethnic families and communities to participate in school education development planning, curriculum content development and other activities. Promote effective communication and exchange channels among students, families, communities, and schools, achieve multi-coordination and cooperation in daily educational and cultural activities, and promote students' academic progress.

\section{Developing inclusive and diversity culture}

First of all, with the aid of school education, it should spread the mainstream values and common culture of the society to cross-border ethnic youth. It is necessary to actively play a diversified and effective means for school education, to promote the national spirit and the consciousness of reform and innovation to the cross-border ethnic groups. As well as laws, knowledge of the rule of law, establishing a modern citizenship concept. Strengthen the innovation and 
development of the culture, strengthen the education of the official language, and provide long-term shared social ethics, lifestyle, and cultural identity among ethnic minorities with different ethnic cultures and religious beliefs, including cross-border ethnic groups.

Secondly, develop the schooling to improve the development of cross-border ethnic culture. It should ensure that cross-border ethnic social cultures are compatible with mainstream cultures and avoid nationalist tendencies in ethnic and religious activities and traditional cultural activities. It is necessary to enrich the content of schooling for cross-border ethnic groups and the general public, improve bilingual education and other ethnic education methods.

Finally, it should improve the exchanges among all ethnic groups, and the integration and innovation of ethnic cultures are promoted. In the ethnic areas of the border, it should help students to engage in activities such as sports, literature and art, and friendship, so as to promote mutual learning among students of different nationalities, enhance mutual understanding, learn from each other, and help each other.
Give full play to the basic role of education in the integration and innovation of ethnic cultures. On the one hand, it integrates Chinese fine traditional culture into primary and secondary school teaching materials and classroom teaching. On the other hand, it sets up the courses of ethnic art and sports at schools. Excellent traditional cultural inheritance activities enable traditional ethnic cultures to achieve inheritance and development.

\section{ACKNOWLEDGMENT:}

The National Social Science Fund of China (2017) : The Study On Basic Education and Cultural Identity of

Cross-Border Ethnics in China- Myanmar Border.

\section{REFERENCES}

[1] State Council: The Decision on Developing Ethnic Education. 2015. (In Chinese)

[2] Fei Xiaotong. Chinese : one with Multi-element [M].Central Ethnic University Press. 1999:65. (In Chinese)

[3] Ha Jingxiong, Teng Xing. The Introduction on Ethnic Education [M]. Education \& Science Press. 2001:118. (In Chinese) 